\title{
Gap Acceptance, and Traffic Safety Analysis On U-Turn Median OpeningsOf Arterial Roads
}

\author{
Dr. Abdul Khalik Al-Taei \\ Assistant Prof. Trans Engineering \\ Civil Engineering Dept / College of Eng. \\ University of Duhok
}

ABSTRACT

In this study, eight locations on U-turn median openings in Duhok City were investigated about gaps or lags of traffic opposing and delaying traffic turning left. Other data was collected from the scene like conflicts with turning traffic, travel speed, and volumes of opposing and parallel flow. Accident frequency experienced near U-turn openings location for three years (2005-2007) was collected too.

Analysis of data using statistical methods show different empirical models correlating independent variables like, gap length travel speed, traffic volume, approach width , conflict rate...etc. with dependent variables like, delay time, accident rate, and percentage of drivers accepting or rejecting gaps . Average lag obtained to control safety of studied locations was $3.5 \mathrm{sec}$.

Key Word: Gap Acceptance, Duhok

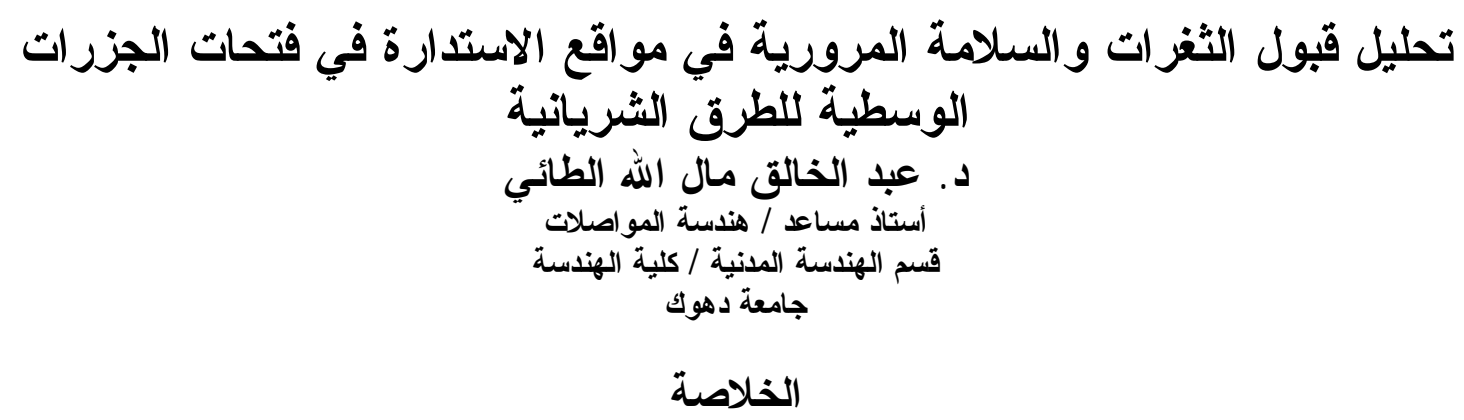

في هذه الدراسة تم تحديد وجمع البيانات من ثمانية مواقع في فتحات الجزرات الوسطية في مدينة دهوك مثل

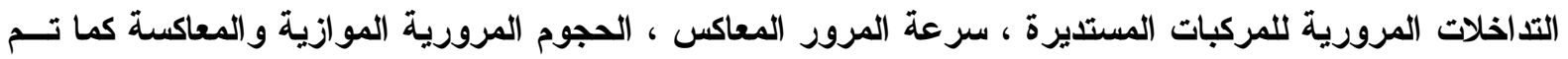
جمع ترددات الحوادث المرورية الحاصلة خلا ثلاثة سنوات (2005-2007) بالقرب من مواقع الدراسة تم جمعهــا

تم تحليل البيانات بالطرق الإحصائية وتم العصول على مجموعة من الموديلات الرياضية الافتر اضــية ذات العلاقة التي تربط المتغيرات غير المعتمدة مثل طول الثغرات المرورية ، سرعة المركبات ، كمية الجريان المروري

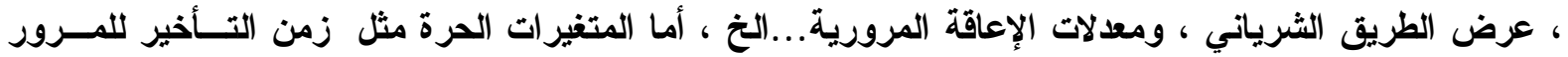

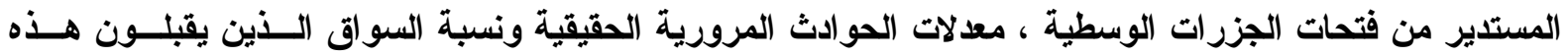
الثغرات المرورية وينفذون الاستدارة ونسبة السواق الر افضين لها أي المنتظرين لثغرة مناسبة. من خلال التحليل تم الحصول على معدل قيمة الثغرة الواحدة في كافة المواقع المشمولة بالدارسة وقدرها 3.5 ثانية والتي تحقق متطلبات السلامة المرورية. الكلمة المفتاحية: دهولة المروية ، قبول الثغرات 


\section{Introduction}

Congestion and delay time are the main problems influencing flow of traffic on most of uncontrolled intersections.

This matter was studied for long time before by many authors interested in traffic flowon uncontrolled intersections having different geometrics. Flow of traffic inside city road networks is suffering from a truly serious problem of traffic making left turns on median openings. These opens on medians are used by traffic management officers to reduce the number of signalized intersections within the city road networks. Problems influenced are usually related to the delay time and queues developed due to the accumulation of vehicles tending to make left turns (i.e., U-turns). Drivers are suffering from long time delays especially if the opposing flow is heavy and gaps between successive vehicles are small. Drivers are not able to use short lags of time to continue their turning.

Sometimes accidents happen on these median openings, and traffic agencies enforced to close them for a certain period of time. However, traffic accidents happening on these hazardous locations are usually fatal accidents type for passengers seating besides the driver or behind him or even serious injury accidents for others involved. Cars are usually highly damaged during these accidents especially if the attacking is heavy vehicle. Accident statistics are showing severe hazard for vehicles using median openings containing no control or police men directing traffic flow.

\section{Purpose of study}

Drivers are encountering serious and hazardous situation during left turn on median openings coming from one or both directions if the opening is wide. Drivers are usually become indignant due to waiting long time stopping and enforced to reject short gaps (i.e. lags) between high speed vehicles opposing left turn vehicle movements.

Conflicts are the main events facing drivers in the scene mostly due to friction among vehicles tending to accumulate on this situation. To mitigate accidents and reduce conflicts, in depth study is required in this case. Sometimes traffic officers requiring convenient solutions to solve the problem. Type of control sign or signal required can be selected out of a deep observation of flow near the above locations.

Theoretical research work may be needed to simulate the situation of traffic during dynamic flow of vehicles. To conduct such study, a practical data is usually needed to assist the theoretical solution.

\section{Review of literature}

In the literature investigated, little amount of research work had been conducted to describe flow on such locations. Diagnosis of the hazardous situations is needing collection about the main traffic parameters necessary to analyze the situation.

At uncontrolled intersections of any geometry, the probability of an approaching vehicle being delayed, and the amount of delay depends on traffic volumes on various approaches, sight distances available, and gap size acceptable to approaching drivers (1).

Jacques H. (1963), observed queues of vehicles which each come to a stop at stop sign had shown that the median minimum departure headway with no cross street interference was 4 sec. (2).

Salman N.K. , and Taha, T., investigated on of the most dangerous left turn median opening in Al-Rashidia roadway from Al-Asabi major street in Mosul city. The study found that the critical gaps for turning vehicles was (6.2) sec. and the gap distribution was very well fitted with gamma distribution (3). 
Blunden et al (1962), have attempted to fit Erlang distribution to rejection, or acceptance between theoretical and observed gaps using k-factor values for Erlang equation of (6), (4). He proposed two methods for sample size considerations.

Ashworth R.(1970), had demonstrated that Blunden's results biased with normal field practice. The unbiased estimate of the mean of the critical gap distribution may be obtained by subtracting $\left(\mathrm{S}^{2} \mathrm{q}\right)$ from the $50^{\text {th }}$ percentile acceptance gap, where $\mathrm{S}^{2}$ is the data normal variance and $\mathrm{q}$ is the flow in vehicles / sec (5).

Highway capacity Manual (HCM-2000), uses the critical gap (i.e., the minimum time that allows intersection entry for one-minor street vehicle), as an important element in computing potential capacity for uncontrolled intersection (6). Base critical gap , is usually used to find out the level of service of each lane group on each intersection approach. HCM estimated that lag as (4.1) sec. on both two and four lane major street approaches.

\section{Data collection:}

In order to collect data about gaps and how they are going to be distributed at median openings, eight locations were selected to perform data collection program. Locations selected are shown in figure (1) which is showing the random selection of those locations on multi-lane arterial streets passing through Duhok city urban area (7). Types of data gathered can be classified as follows:

\section{Gap and Lag}

Locations were observed using digital camera for a period of time between half to one hour at peak morning demand showing both directions of flow. Vehicles waiting to turn were photographed and how they were going to match with the opposing major traffic of high speed . Out of this scene, gaps, speeds of major flow were counted using time-lapse pictures one by one. Gap is the time period considered from rear bumper of front vehicles up to the front bumper of the car following. Meanwhile speed was computed using time difference location on the menu of (50) meters space between successive vehicles. Flow rate was counted through this process as well.

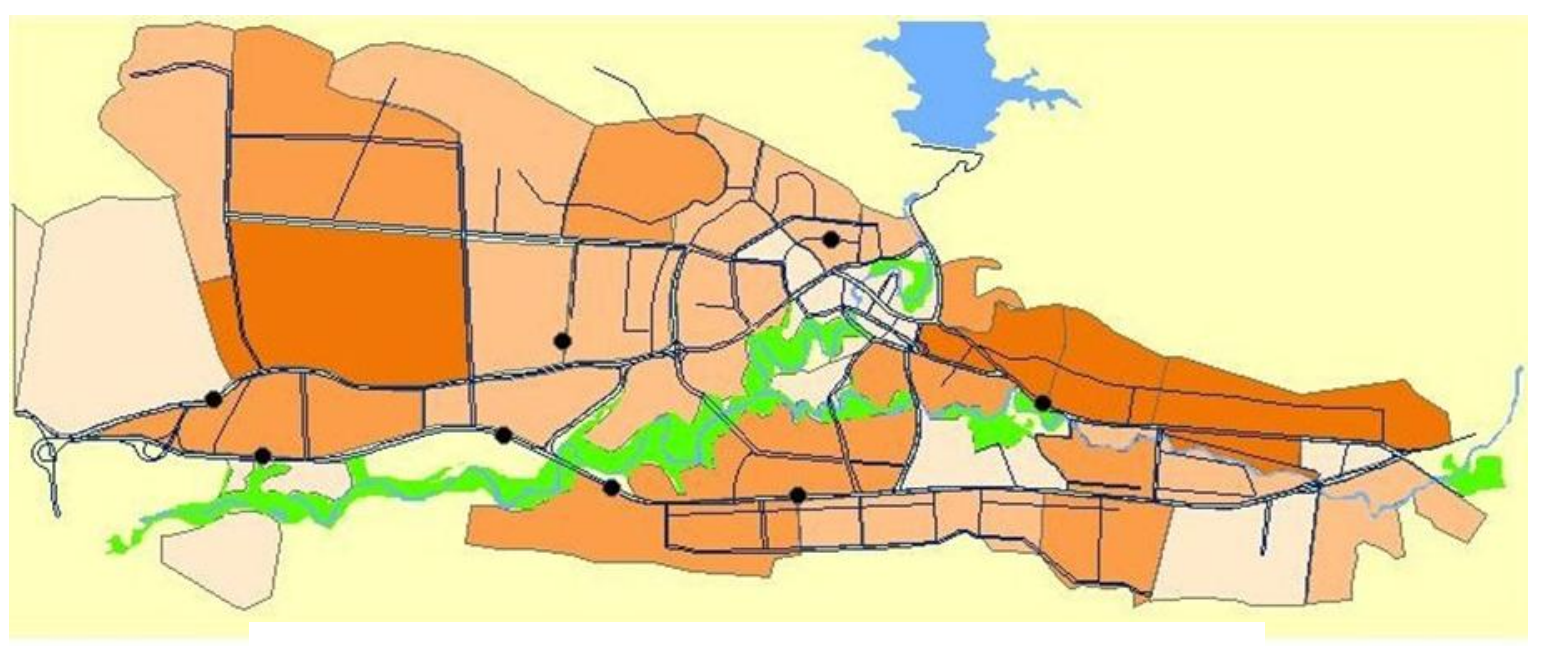

- Locations of U-Turn Median Lane Openings

Figure (1): Duhok City Road Network and U-Turn Median Lane Opening Location Included in the Study. 
On median opening, vehicles tending to accumulate and wait for turning were counted for each chance of accepting a gap on major street traffic. Some openings contain double turning directions, one for north direction turn to south, and vice versa. Each direction was treated as a separate case study and included in this process.

\section{Conflict Frequency}

Photographs taken out of the scene were observed again to count the conflict type and frequency between traffic coming from opposing direction with high speed, and the other making U-turn conflicts type I, and type II. Type I conflicts are those happened with a car shy away due to high sound brake, or horns, but conflict II was just high light signal or speed reduction reaction by high speed opposing flow. Special conflict count forms were used to count both conflict type numbers (8).

\section{Geometric Data:}

Some geometrics were observed to correlate them with other traffic flow parameters in this study. Road types containing U-turn openings are four-lane arterials with different volumes of traffic and signalized intersections located along them. Approach width, where traffic passing within different lanes was considered as a variable in this study. Arterial approach widths located within Duhok city streets are between (7.0), and (12.0) meters in each direction of separated flow.

Process of study and data collection program is shown in figure (2).

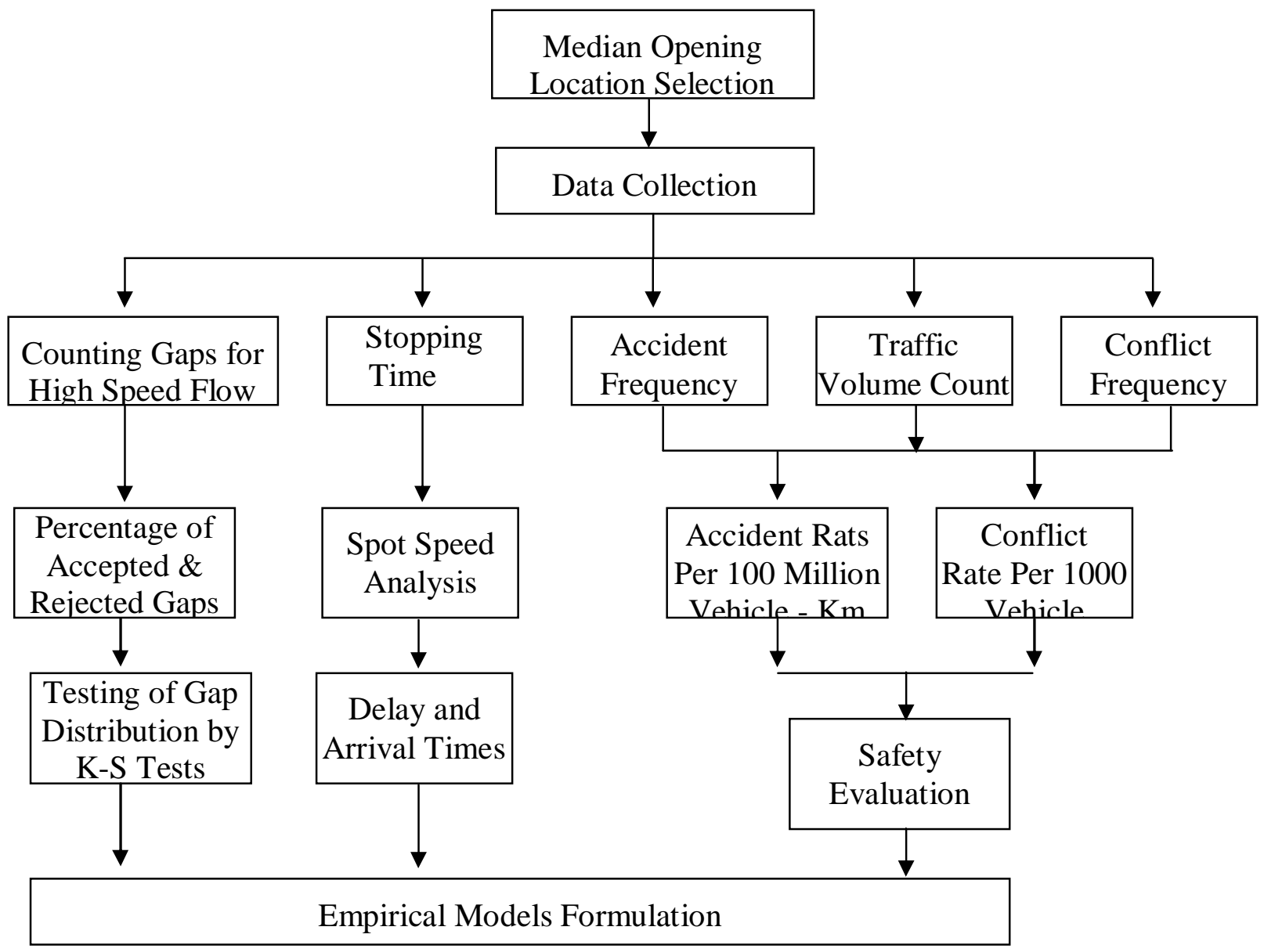

Figure (2): Study Flow Chart 


\section{Accident Frequency}

Traffic accident records published in the Duhok Traffic Directorate have been investigated and compiled from accident records (9). Accident records were found necessary to compute accident rates per (100) million vehicle-Kilometers.

Accident statistics for the locations included in this study were collected for the period of three years between (2005-2007) in order to correlate accident rates with conflict rates.

Conflicts are usually considered as surrogate to accidents in the safety evaluation of any specific location as they need shorter period of time to be counted than accidents (8).

\section{Analysis of Results}

In this study different parameters are correlated to each others to formulate the process of queuing of vehicles at U-turn openings of arterial median lane. Some computer software packages were used in this analysis like SPSS 15, and Microsoft Excel to derive some of the complicated empirical models.

\section{Gap Acceptance and Rejection:}

Selected locations observed of both types double, and single U-turn were analyzed using gaps collected data. Drivers deem to wait until an enough lag to be provided to make U-turn. Sometimes waiting was long enough that push the drivers to disobey the rules or signs provided at the scene. All the selected locations were analyzed under this phenomenon of accepting the gap and pass over or rejecting it and stay behind at stop. For example in Malta district the U-turn opening selected is a double, and figure (3) shows both curves of rejecting and accepting gaps in percentage of drivers. Acceptance curves are starting from nil up to one second then decreases. Summation of both probabilities to pass or still stop is unity at any point. Point of intersection of both curves denotes to the critical gap (i.e. , lag) of( 3.5)sec. which is the critical period between successive on coming vehicles in the major street. Drivers were not able to pass with a gap less than it.

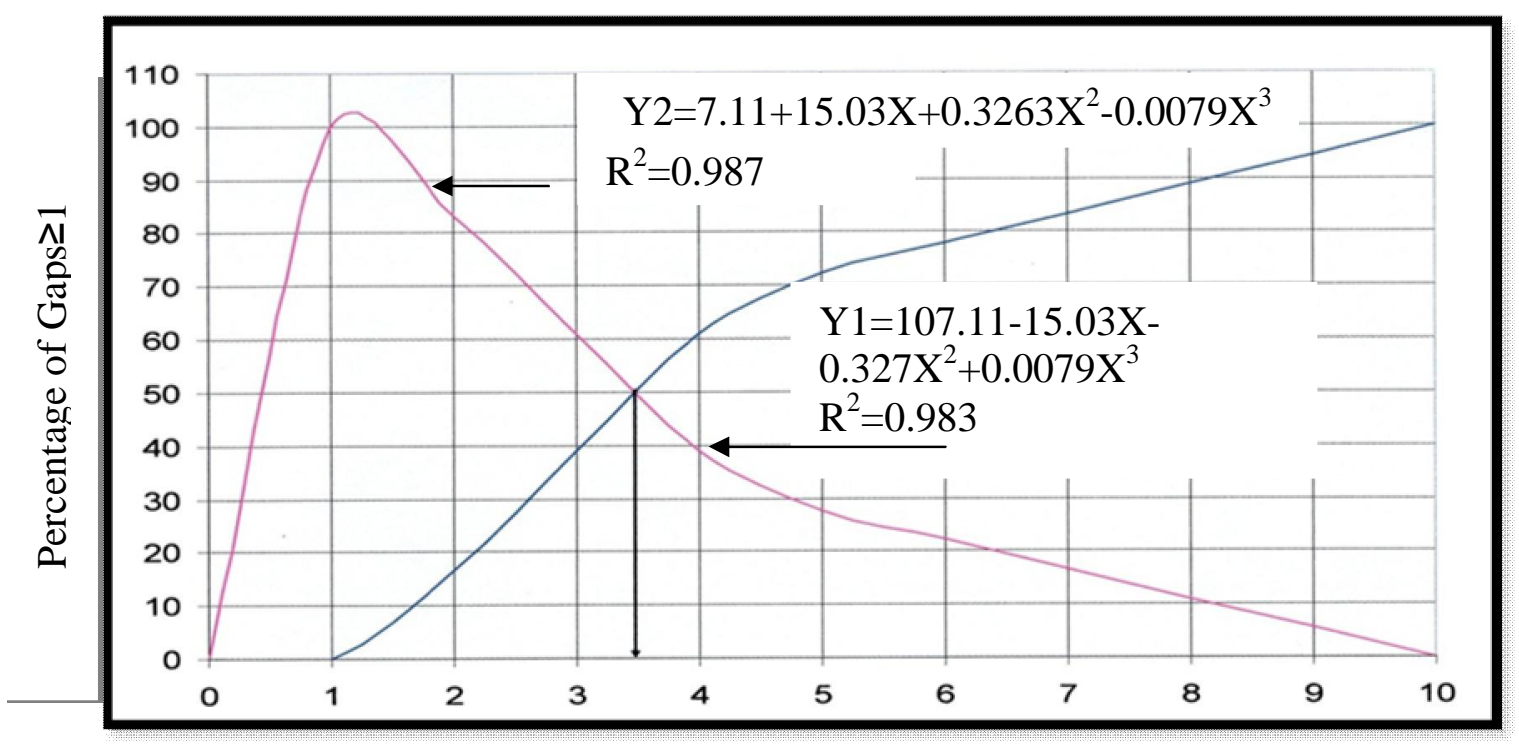

Figure (3): Percentage of Gaps $\geq t$ and Gap Length in (Sec).Near Malta District UTurn Median in Duhok City. 
Statistical analysis shows that both accepted and rejected curves are third degree polynomial function with high correlation coefficient of 0.987 and 0.983 respectively. On some other locations, critical gap was less than 3.5 Sec. Like Shandokha, and Baroshki U-turn openings.

On openings near Duhok secondary school Garibasi, and office of Agriculture Directorate, critical gaps observed were higher than $3.5 \mathrm{Sec}$. Out of this result. It can be concluded that on heavy trafficked street, critical gaps are tending to be shorter, mean while at lower congested streets, the critical gap seem to be longer than critical.

In general, average critical gap observed in this study along all studied locations was 3.5 Sec. Analysis of variance shows that, variation of results is high by using digital camera method in collecting data.

Gaps as random events were tested using some advanced statistical distributions. Testing of hypothesis shows that, gaps are distributed under Erlang function of the shape:

$$
\mathrm{P}(\mathrm{h} \geq \mathrm{t})=\sum_{\mathrm{i}=0}^{\mathrm{k}-1}\left[1+\left(\frac{\mathrm{kt}}{\mathrm{T}}\right)\right] \frac{\mathrm{e}^{-\mathrm{kt} / \mathrm{T}}}{\mathrm{i} !} \quad \text { Where: }
$$

$\mathrm{P}(\mathrm{h} \geq \mathrm{t})=$ probability that gap size is more than certain time $\mathrm{t}$.

$\mathrm{h}=$ gap size in seconds.

$\mathrm{k}=$ shape factor of the function. $(\mathrm{k} \geq 2)$.

$\mathrm{T}=$ Total period of observation in seconds.

From the analysis k-factor size of (4), was computed from real data of gaps with their frequencies on some locations considered in fitting this distribution.

Erlang distribution which is one type of Gamma distribution function was found excellent in fit with gap data using Kolmogrov-Smirnov test (i.e. K-S test). K-S test is already more powerful than $\chi^{2}$ test if sample size is small (10).

\section{Delay Time at U-Turn Openings:}

Delay time period due to stopping of vehicles deem to make U-turn was observed at the time lapse photo.

Delay was averaged in a number of seconds a vehicle delayed under the operating circumstances of the opening, from stop to start.

Some of these delays were long enough at certain periods of flow that closure of opening is more useful. Drivers become diligent and try to make severe conflicts with major high speed traffic in order to pass.

Figure (4) shows the relationship between delay time of idling vehicles and average travel speed on major street traffic. Third degree polynomial was the best fit with low $\mathrm{R}^{2}$ value and high standard deviation. It is a sine wave curve with lower delay at $(50-55) \mathrm{km} / \mathrm{hr}$ speed of major traffic, and higher delay at (80-85) $\mathrm{km} / \mathrm{hr}$. ,due to stopping of high speed traffic impeded by turning traffic.

Figure (5), is correlating delay time with approach width of arterial at the U-turn opening locations. The relationship is a sin wave too, and third degree polynomial with low $\mathrm{R}^{2}$ value and high standard deviation was obtained. The figure, shows that arterial approach width of $(7.5-8.5) \mathrm{m}$ and delays of traffic tending to make U-turn flow highly correlated, but at wider approaches of (11-12) m delays are less correlated due to high impedance at narrow lanes.

Figure (6), shows the relationship between delay time, and average conflict rates computed for each 1000 vehicles of highway flow. The curve is w-shape, with lower delays at lower, and higher conflict rates of (5.5) and (13.5), respectively, but optimum at 9.5 conflict rate. The model is a third degree polynomial too with low $\mathrm{R}^{2}$ value and high standard 
deviation, this is mainly due to less chance for conflicts to happen with lower flows of through traffic.

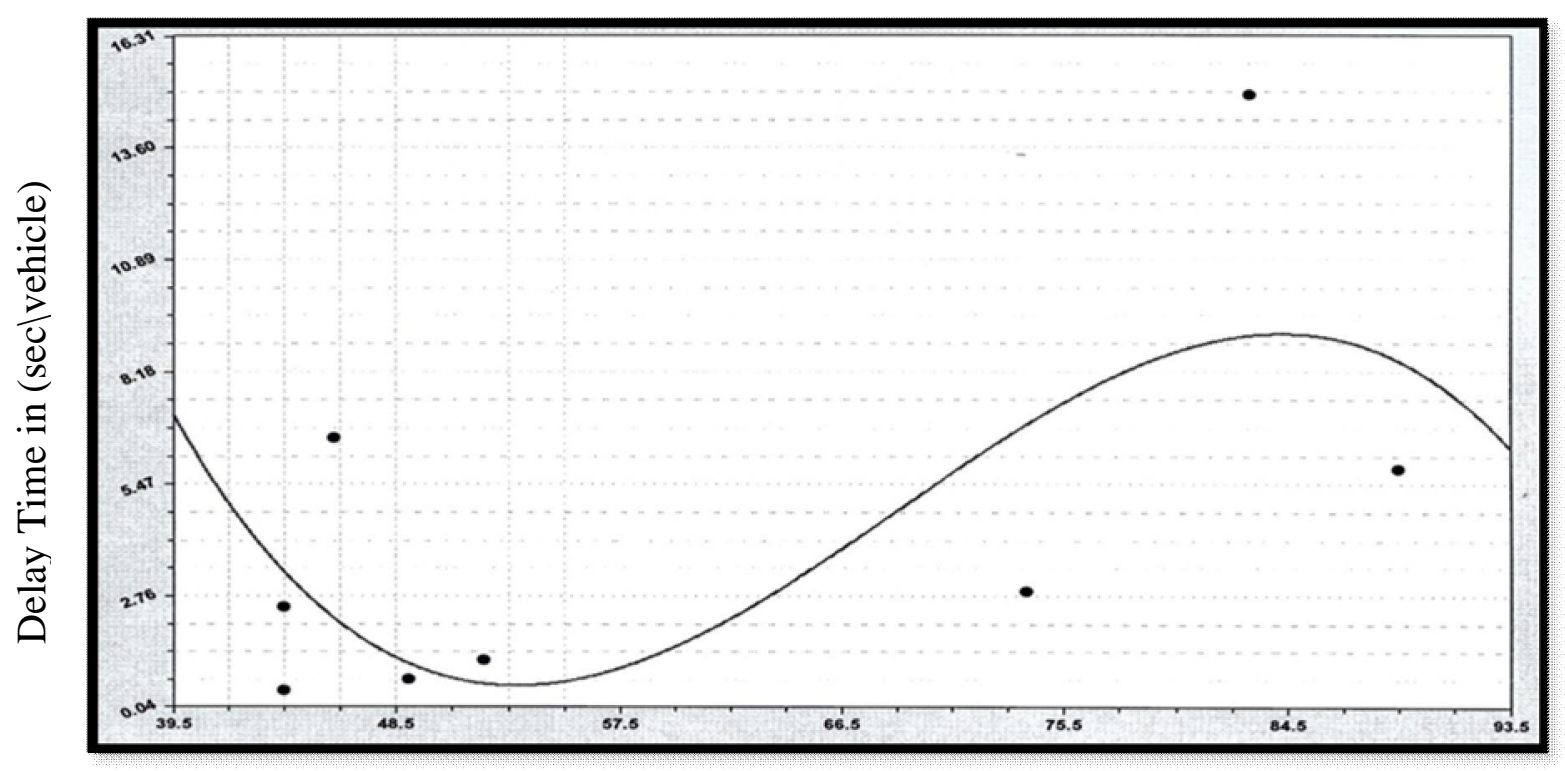

Average Travel Speed $(\mathrm{km} / \mathrm{hr})$

Figure (4): Delay Time, and Travel Speed in $\mathrm{km} / \mathrm{hr}$ on U-Turn Median Openings in Duhok City

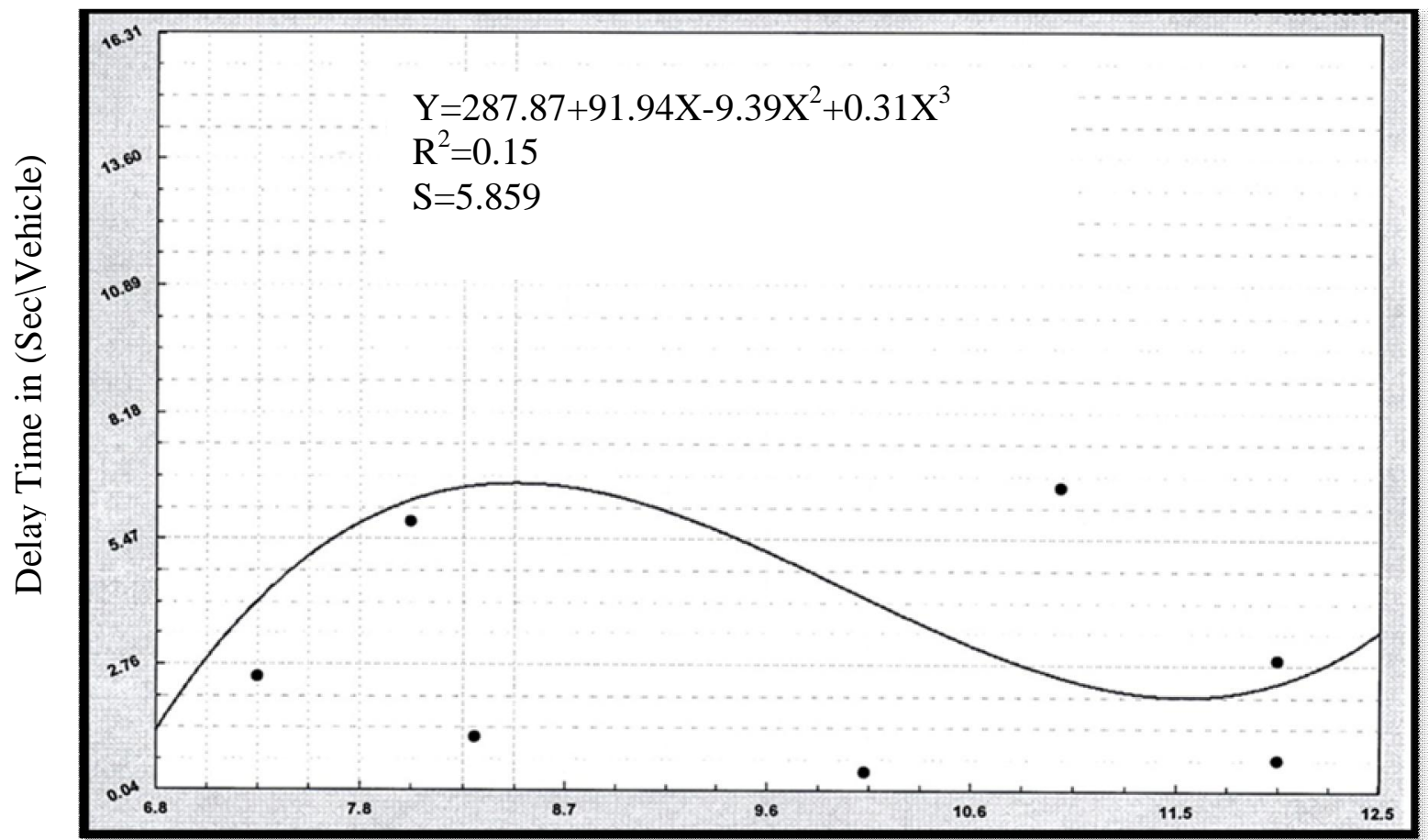

Road Width in (m)

Figure (5): Delay Time, and Road Width at U-Turn Median Openings in Duhok City 


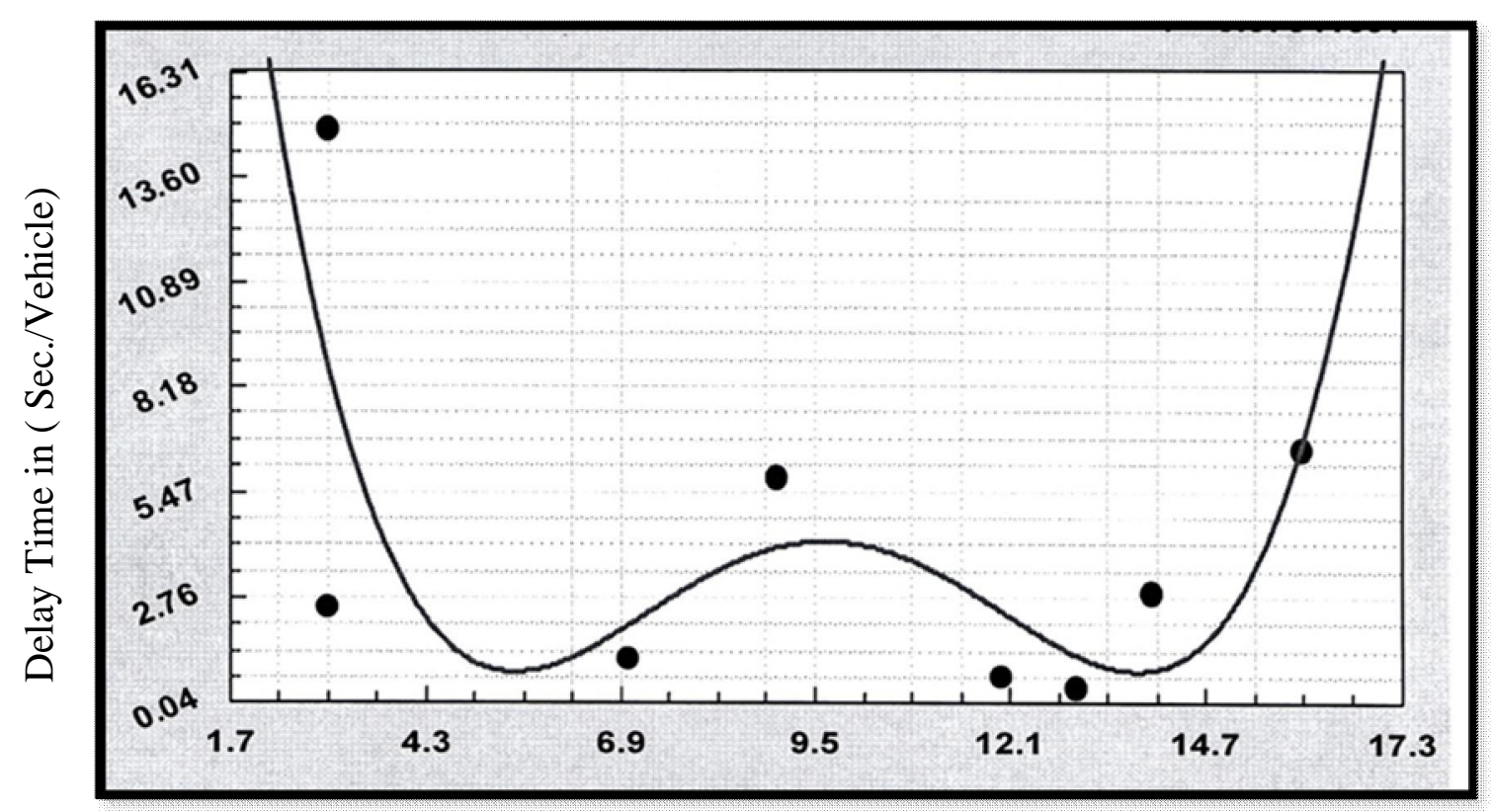

Figure (6): Delay Time, and Average Conflict Rate on U-Turn Median Openings in Duhok City

Figure (7), shows an exponential curve relating delay time of vehicles waiting for Uturn and the flow of the opposing direction volume mixed traffic. The positive correlation coefficient obtained is good with high error of estimate reflecting the truth that delay of vehicles is increasing relative to the increase in opposing flow (i.e., low number of chances or shorter gaps are provided to pass).

Figure (8), describes the U-shape third degree polynomial model between accident rates per million vehicles happened near the U-turn opening locations collected during three years of traffic operation as recommended by ( 8 ), and average travel speed of traffic. Minimum accident rate is obtained at speed of $(45-50) \mathrm{kph}$ which is the reliable, and safe speed that should be recommended to be used by drivers in urban streets. The relationship is correlating accidents and speeds with relatively low standard deviation.

Accident data was not sufficiently reliable to fit a subjective model relating safety at the U-turn openings.

Figure (9), shows the same above principle relating accident rates per million vehicles passing the section where U-turn openings is located, and conflict rates per 1000 vehicles of the same traffic.

The model is a cosine-shape with moderate $\mathrm{R}^{2}$ of $(0.7)$ and relatively low standard deviation. The figure demonstrates the truth that conflicts may be used as a surrogate data in place of accidents to describe safety condition near U-turn openings of arterials. 


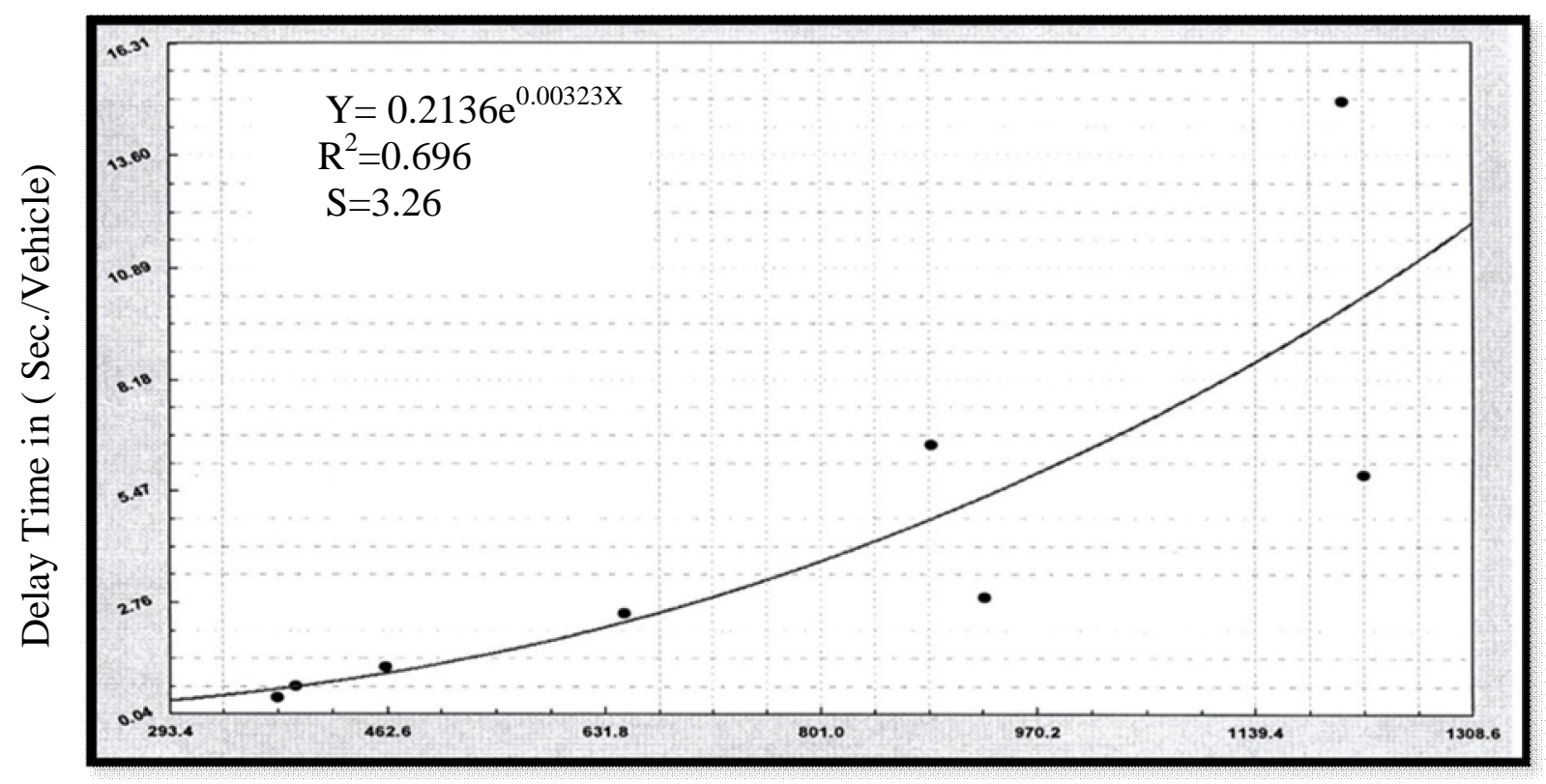

Traffic Volume in (vph)

Figure (7): Delay Time, and Traffic Volume on U-Turn Median Opening in Duhok City

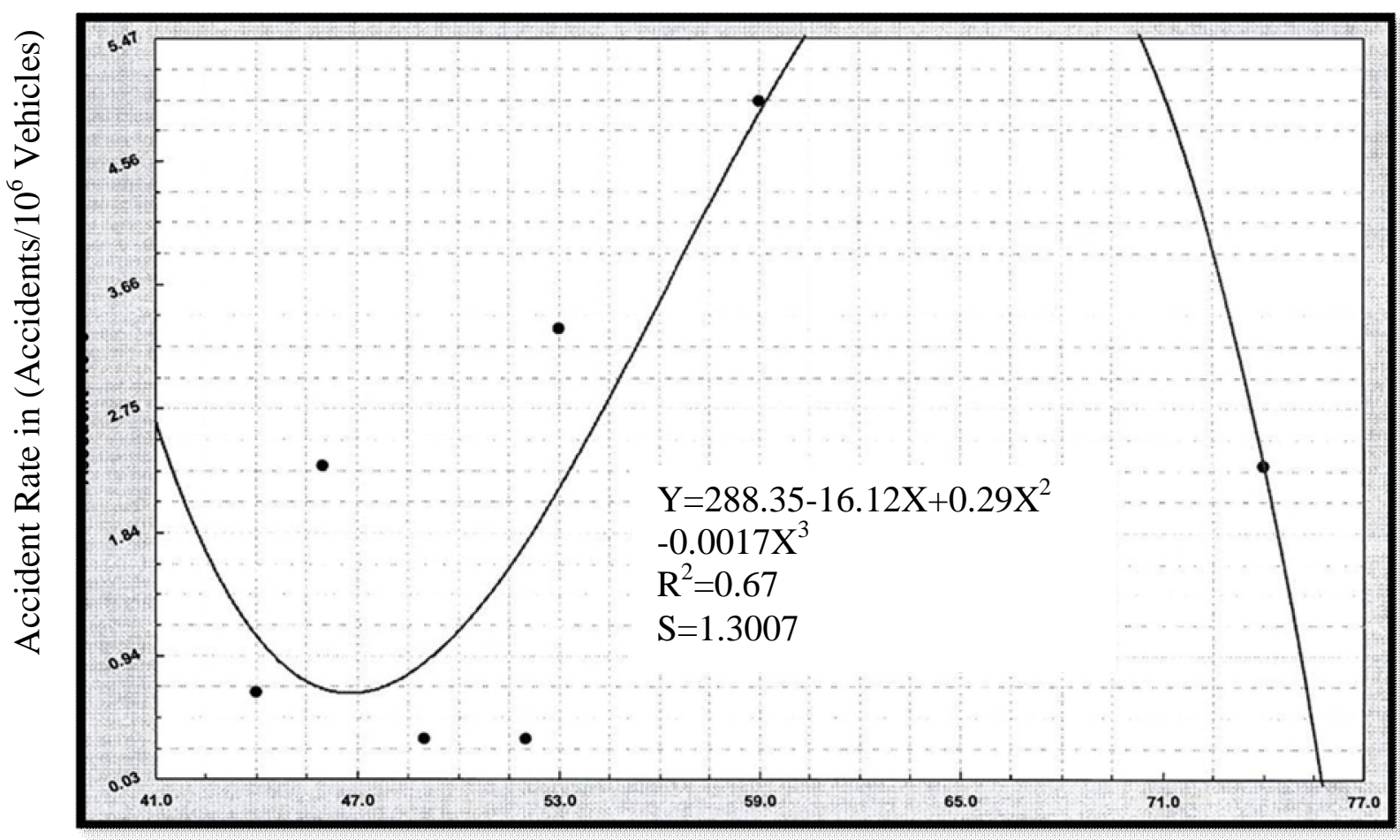

Average Travel Speed $(\mathrm{km} / \mathrm{hr})$

Figure (8): Accident Rates and Average Travel Speed on U-Turn Median Opening in Duhok City 


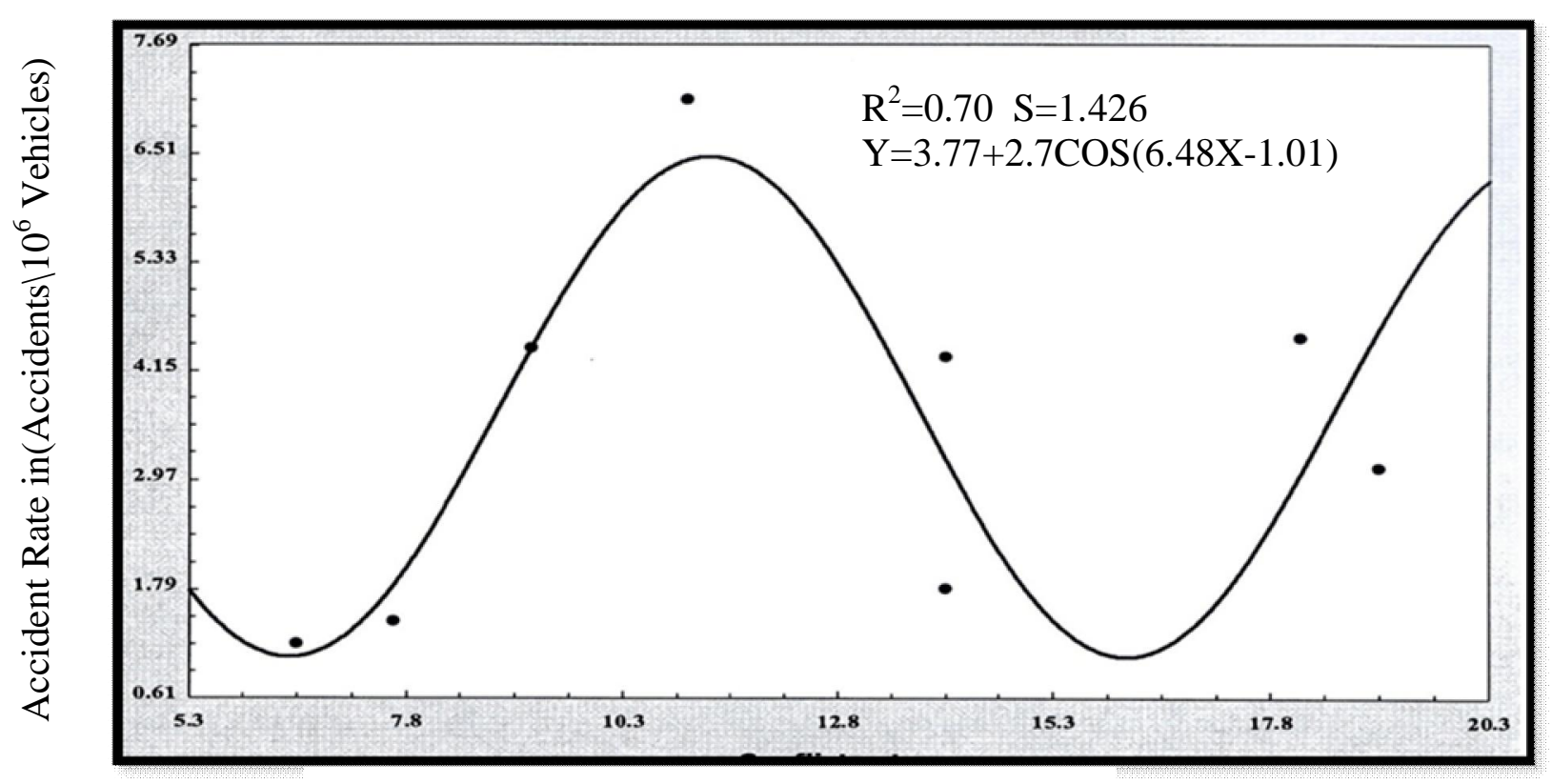

Conflict Rate in Conflicts $\ 1000$ vehicles

Figure (9): Accident Rates, and Conflict Rates on U-Turn Median Openings in Duhok City

Accident rates and average volumes at the U-turn openings are positively correlated exponentially with sufficiently high $\mathrm{R}^{2}$ of $(0.87)$ and low standard deviation. Figure (10) ,shows the relationship described above near the U-turn openings in urban arterials.

Average travel speed and approach width near U-turn openings are directly increasing with good correlation coefficient of (0.63) and low standard deviation. Reciprocal function is the better choice relating them. Figure (11) shows the above correlation.

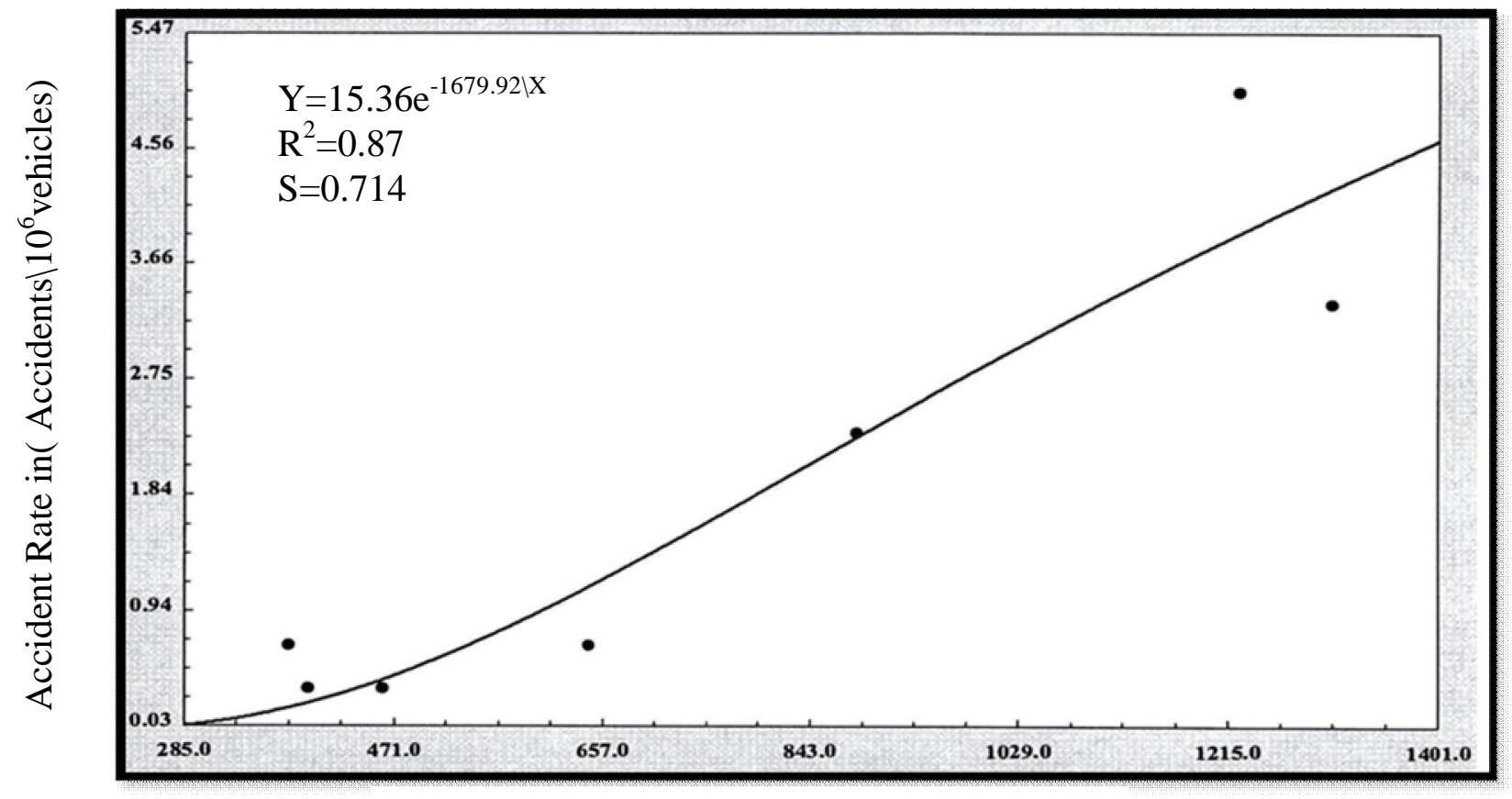

Average Traffic Volume in (vph)

Figure (10): Average Accident Rate, and Average Traffic Volume on U-Turn Median Openings in Duhok City 


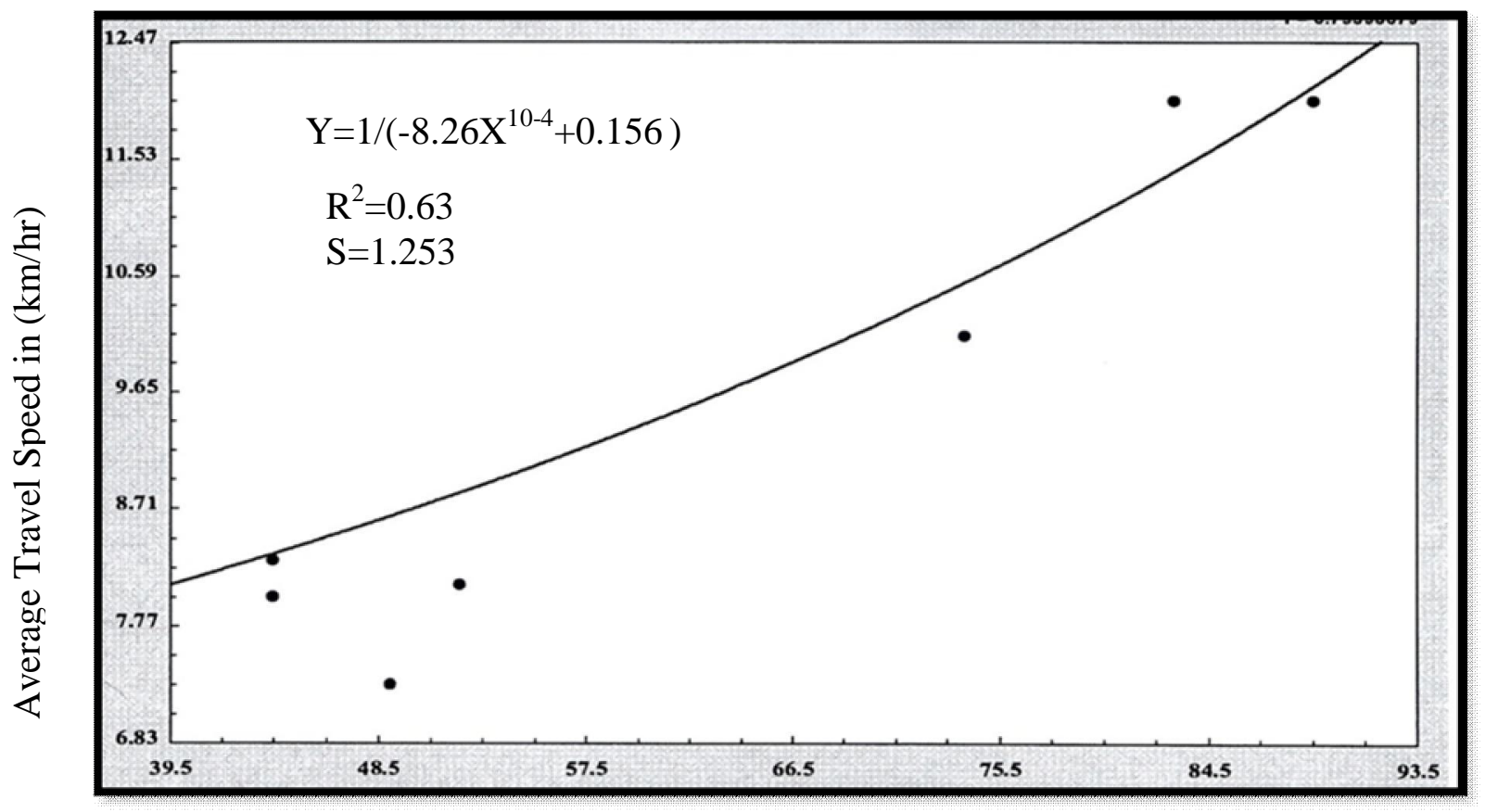

Average Approach Width in (m)

Figure (11): Average Travel Speed and Average Approach Width of Arterial Road on U-Turn Median Opening in Duhok City

\section{Conclusion}

Under the circumstances of data collection equipment and study staff experience, on Uturn median lane openings on arterial streets on Duhok city road network the following conclusions can be drawn out:

1- Empirical models showing the trend of accepting and rejecting gap or lags by drivers on U-turn median lane openings are third degree polynomials with high $\mathrm{R}^{2}$ value more than 0.97 .

2- Average critical gap period observed on U-turn median lane openings on arterials is 3.5 sec only.

3- At highly congested U-turn locations, critical gaps observed are shorter than $3.5 \mathrm{sec}$ but longer at other locations.

4- Lower delays are observed at (50-55) $\mathrm{km} / \mathrm{hr}$, and higher delays resulted at $(80-85) \mathrm{km} / \mathrm{hr}$ of major or street traffic speed.

5- Lower approach width are passively affecting delays of traffic trying to make U-turn at median openings. Wider approaches are actively affecting time loss, for turning traffic.

6- Delay are low at lower and higher conflict rates and high at moderate values of conflict rates of 9.5 conflicts / 1000 vehicles.

7- Delay time is usually tending to increase with the increase in the flow of traffic from opposing direction with high correlation coefficient.

8- Minimum accident rate obtained is 0.7 accident / million vehicles at travel speed of (4550) $\mathrm{km} / \mathrm{hr}$ on arterial roads with moderate power of correlation.

9- Accident rates / million vehicles, and conflict rates / 1000 vehicles are positively correlated. This correlation means that, conflicts may replace accidents data in safety evaluation of U-turn median lane openings on arterials.

10- Exponential model is correlating accident rates / million vehicles and traffic flow of opposing direction of turning with relatively high correlation factor of $(0.87)$. 


\section{Recommendations:}

Out of the results obtained from the analysis of data collected and correlated in this study of traffic operation on U-turn median lane openings on arterials the following recommendations can be drawn out:

1- At locations where gaps become less than average value obtained of $3.5 \mathrm{sec}$, for long period of time and delay become more than $5 \mathrm{sec} / \mathrm{vehicles}$, closure of that openings is better as severe conflicts may be started.

2- Data and models obtained in this study are able to simulate traffic operation on this dangerous parts of arterial street. Models can be introduced in a dynamic simulation process using non-fixed interval method.

3- Same study is recommended to be implemented from time to time to provide decisions highlighting safety on U-turn median lane openings.

4- Stop signs, mirrors and separated median lanes (i.e, by raised islands), are recommended at locations of high congestions and short lags for turning traffic to pass.

5- Safety breaking down of one accident per year is enough to close traffic operations on Uturn median lane openings.

\section{References:}

1- Baerwald, J.E. "Transportation, and Traffic Engineering Handbook" , Institute of Traffic Engineers , Prentice Hall Inc. Englewood cliff, New Jersey, 1976.

2- Jacques, H. "A study of four-way stop Intersection capacities" , Highway , and Interchange capacity , HRR27 Washington D.C. , HRB 1963, PP: (130-147).

3- Salman N.K. , and Taha T., "Gap and Lag Acceptance at Uncontrolled Interactions in Mosul" , International Arabic Engineering conference (4-6) April Aman , Jordan 1988.

4- Blunden, W.R, " Clissod , C.M., and Fisher R.B. , "Distribution and Acceptance Gaps for Crossing" Australian Road Research Bound, PP. (188-205), 1962.

5- Ashworth , R. , "The Analysis and Interpretation of Gap Acceptance Data", Transportation science , 4, Vol. (3). , (270-280), 1970.

6- Institute of Traffic Engineers", Highway capacity Manual, Special Repot TRB 209, 2000.

7- Duhok Municipality Directorate" , Master plan comprehensive study of Duhok city" (2007-2008).

8- Federal Highway Administration "Traffic conflict Manual" special report (218-A-90), 1987.

9- Duhok Traffic Directorate "Traffic Accident statistics" , (2005-2007) Duhok city.

10- Richard H. McCuen, "Statistical Methods for Engineers" , University of Maryland, Prentice-Hall Inc. , Englewood cliff, New Jersey 07632, 1985. 